\title{
PENGUJIAN KELAYAKAN ALAT PELINDUNG DIRI ( LEAD APRON DAN THYROID SHIELD)
}

\author{
Thalia Devi Prama Dani ${ }^{1)}$ Darmini $^{2)}$ \\ ${ }^{1}$ Rumah Sakit Hermina Solo \\ ${ }^{2}$ Poltekkes Kemenkes Semarang \\ E-mail : thaliadp0@gmail.com
}

\begin{abstract}
Radiation Protection Tool in Radiology Departement Of RS PKU Muhammadiyah Yogyakarta there are four Lead Apron and Thyroid Shield. Maintance of Lead Apron and Thyroid Shield has not done well and has not been done by X-ray testing. This study aims to determine maintance of Lead Apron and Thyroid Shield, determine the results of Lead Apron and Thyroid Shield, to determine Lead Apron and Thyroid Shield tests are still feasible to use or not. The kind of research that used is descriptive quantitative research with survey approach. Data collection is done by direct observation, testing, measurement and documentation. The observations were conducted directly an four Lead Apron and Thyroid Shield in Radiology Departement Of RS PKU Muhammadiyah Yogyakarta. The testing was done with radiating all Lead Apron and Thyroid Shield and recorded with Computed Radiography. The data obtained are then analyzed. Appropriatness Lead Apron and Thyroid Shield are not feasible to use if the damage in the form a hole of $2 \mathrm{~mm}$ or area exceeds $3,14 \mathrm{~mm}^{2}$ and damage in the form of fault with a lenght exceeding $4 \mathrm{~mm}$. The results of this research indicate that the maintance of Lead Apron and Thyroid Shield is not done well and correctly. Lead Apron and Thyroid Shield placed hung up, folded and placed not on a special cabinet. According the result Lead Apron and Thyroid Shield can be recognized that there is one Lead Apron is not feasible because it has hole damage in the form of $2 \mathrm{~mm}$ or area exceeds $3,14 \mathrm{~mm}^{2}$ and damage in the form of fault with a lenght exceeding $4 \mathrm{~mm}$. But for Lead Apron A, B, D and Thyroid Shield although there are indentation and fractures but not exceeding the specified standart so it is still feasible to use.
\end{abstract}

keywords: Maintance, Lead Apron and Thyroid Shield,testing

\section{Pendahuluan}

Wilhelm Conrad Rontgen seorang ahli fisika di Universitas Wurzburg, Jerman, pertama kali menemukan sinar Rontgen pada tahun 1895 sewaktu melakukan eksperimen dengan sinar katoda. Saat itu ia melihat timbulnya sinar fluorosensi yang berasal dari Kristal barium platinosianida dalam tabung Crookes Hittorf yang dialiri listrik. Ia segera menyadari bahwa fenomena ini merupakan suatu penemuan baru sehingga kemudian dia melanjutkan penelitiannya dan menemukan sinar yang disebutnya sebagai sinar baru atau sinar $\mathrm{X}$. Sinar $X$ adalah paparan gelombang elektromagnetik yang sejenis dengan gelombang radio, panas, cahaya dan sinar ultraviolet, tetapi panjang gelombangnya sangat pendek (Rasad, 2005).
Peraturan pemerintah No. 63 Tahun 2000 tentang keselamatan dan kesehatan terhadap pemanfaatan radiasi pengion dan diatur lagi dengan Keputusan Kepala BAPETEN No. 8 Tahun 2011 tentang keselamatan radiasi dalam penggunaan pesawat sinar- $\mathrm{X}$ Radiodiagnostik dan Intervensional. Peraturan ini bertujuan untuk menjamin keselamatan, keamanan, ketentraman, dan kesehatan para pekerja dan anggota masyarakat, serta perlindungan terhadap lingkungan hidup.

Pemanfaatan radiasi pengion dalam bidang radiodiagnostik untuk berbagai keperluan medik perlu memperhatikan dua aspek, yaitu resiko dan manfaat yang akan di capai. Fakta menunjukkan bahwa diinstalasi radiologi bisa sangat rawan jika pengukuran proteksi dan 
paparan radiasi tidak dilakukan. Dampaknya secara langsung akan dirasakan oleh radiografer dan dampak yang tidak tergantung akan dirasakan oleh masyarakat (Rudi, 2012).

Prinsip-prinsip proteksi radiasi terdiri dari tiga asas proteksi radiasi, asas proteksi tersebut meliputi asas justifikasi, optimisasi dan limitasi. Asas justifikasi ini setiap kegiatan yang berhubungan dengan paparan radiasi harus dilakukan pengkajian yang cukup mendalam. Sedangkan asas optimisasi sering dikenal juga dengan prinsip ALARA ( As Low As Reasonably Ashievable) serta asas limitasi agar dosis yang diterima tidak melebihi nilai batas dosis yang telah ditetapkan dan semua resiko paparan radiasi yang cukup tinggi dapat ditangani (Akhadi, 2000).

Alat Pelindung Diri (APD) merupakan kelengkapan yang wajib digunakan saat bekerja sesuai dengan resiko kerja untuk menjaga keselamatan pekerja itu sendiri dan orang disekelilingnya. Alat Pelindung Diri yang digunakan oleh pekerja radiasi adalah sarung tangan $\mathrm{Pb}$, Gonald Shield, Thyroid Shield dan Lead Apron ( Yulihendra, 2002).

Lead Apron yang mampu menahan paparan radiasi biasanya memiliki ketebalan timbal minimum setara $0,35 \mathrm{~mm}$ digunakan untuk bagian depan tubuh dari tenggorokan sampai ke lutut dan dengan ketebalan timbal setara $0,25 \mathrm{~mm}$ untuk menutupi bagian belakang (Lambert, 2001).

Perawatan Alat Pelindung Diri sangat penting agar tidak terjadi kerusakan ataupun patahan internal. Kesalahan yang sering terjadi dalam perawatan Alat Pelindung Diri seperti meletakan di atas punggung kursi, menggantungkan secara vertikal dengan hanger, dan meletakan dengan cara ditumpuk akan menyebabkan menyebabkan patahan internal dan mengalami kerusakan akibat gravitasi. Ketika Alat Pelindung Diri tidak digunakan, maka sebaiknya diletakkan dengan posisi horisontal dan tidak ditumpuk ( Grover, 2002).

Menurut Grover (2002) pengujian Lead Apron dapat dilakukan 1 tahun sekali sesuai dengan kebutuhan. Untuk sinar X dibawah 100 $\mathrm{kV}$ ketebalan Lead Apron diatas 0,25 $\mathrm{mm}$ dan apabila sinar $\mathrm{X}$ yang digunakan melebihi 100 $\mathrm{kV}$ ketebalan Lead Apron diatas 0,35 mm (Brennan P, 2005).

Di Instalasi Radiologi Rumah Sakit PKU Muhammadiyah Yogyakarta mempunyai 4 buah Lead Apron dan 1 buah Thyroid Shield. 4 buah Lead Apron ini tidak dibeli secara bersamaan sedangkan Thyroid Shield dibeli 2013. Lead Apron yang pertama berada diruang pemeriksaan 1 yang dibeli pada tahun 1997 dengan ketebalan Lead Apron 0, $35 \mathrm{~mm}$ serta ketebalan bagian belakang $0,25 \mathrm{~mm}$ dan diletakan dengan cara digantung dengan menggunakan hanger baju. Lead Apron yang kedua berada diruang pemeriksaan 2 dibeli pada tahun 2016 dengan ketebalan Lead Apron 0,35 mm dan diletakan dengan cara di sandarkan di balik tabir $P b$ dengan posisi terlipat bagian tengah. Lead Apron yang ketiga berada di ruang pemeriksaan CT Scan dibeli pada tahun 2007 dengan tebal Lead Apron 0,35 $\mathrm{mm}$ serta ketebalan bagian belakang $0,25 \mathrm{~mm}$ dan diletakan secara tidak beraturan. Lead Apron yang keempat diletakan di ruang ICU dibeli pada tahun 2007 dengan tebal Lead Apron 0, 35 serta ketebalan bagian belakang $0,25 \mathrm{~mm}$ dan diletakan dengan di sandarkan di balik tabir $\mathrm{Pb}$ dengan posisi terlipat bagian tengah. Sedangkan untuk peletakkan Thyroid Shield yaitu dengan cara dilipat-lipat dan dimasukan pada lemari obat pada ruang pemeriksaan 1 . Lead Apron dan Thyroid Shield belum pernah dilakukan pengujian sebelumnya oleh petugas Instalasi Radiologi RS PKU Muhammadiyah Yogyakarta. Dengan cara penyimpanan alat pelindung diri tersebut mudah terjadi kerusakan pada $P b$ yang ada didalam Lead Apron, karena Lead Apron yang terbuat dari $P b$ seharusnya disimpan dialmari khusus dengan cara direntangkan. Lead Apron dan Thyroid Shield yang berada di Instalasi Radiologi RS PKU Muhammadiyah Yogyakarta mempunyai kondisi fisik yang masih baik jika dilihat dengan mata telanjang namun tetap masih harus dilakukan pengujian karena menurut Kepmenkes No.1250/Menkes/SK/XII tahun 2009, pengujian alat pelindung diri dilakukan setiap setahun sekali.

Di Instalasi Radiologi RS PKU Muhammadiyah Yogyakarta perawatan Lead Apron dan Thyroid Shield tidak menjadi kegiatan rutin ataupun wajib karena dalam pelaksanaannya Lead Apron dan Thyroid Shield hanya dibersihkan ketika terlihat kotor ataupun jarang sekali dibersihkan. Pembersih Lead Apron dan Thyroid Shield sendiri menggunakan Meliseptol Pure. 
Penggunaan Lead Apron dan Thyroid Shield di Instalasi Radiologi RS PKU Muhammadiyah Yogyakarta biasa digunakan oleh radiolog, radiografer dan pengantar pasien. Lead Apron digunakan pada saat pemeriksaan radiologi dengan menggunakan media kontras maupun non kontras misalnya pemeriksaan Uretrocytografi atau pada pasien-pasien yang non kooperatif.

Berdasarkan latar belakang diatas, penulis tertarik untuk mengkaji lebih dalam tentang kondisi fisik, profil, hasil pengujian, kelayakan serta perawatan terhadap Lead Apron dan Thyroid Shield yang digunakan di Instalasi Radiologi RS PKU Muhammadiyah Yogyakarta. Agar Lead Apron dan Thyroid Shield tersebut dapat melindungi petugas dari bahaya radiasi maupun pengantar pasien dari bahaya radiasi dan menjadikan sebagai Karya Tulis Ilmiah yang berjudul "PENGUJIAN KELAYAKAN ALAT PELINDUNG DIRI (LEAD APRON DAN THYROID SHIELD) DI INSTALASI RADIOLOGI RUMAH SAKIT PKU MUHAMMADIYAH YOGYAKARTA

\section{Metode}

Jenis penelitian yang digunakan dalam penelitian ini adalah penelitian kuantitatif dengan pendekatan survey yaitu penulis melakukan pengamatan dan pengujian Alat Pelindung Diri di Instalasi Radiologi RS PKU Muhammadiyah Yogyakarta untuk mengetahui kelayakan Alat Pelindung Diri (Lead Apron dan Thyroid Shield) kemudian dilakukan pembahasan lebih lanjut dan ditarik kesimpulan.

\section{Hasil dan Pembahasan}

Penelitian tentang Pengujian Kelayakan Alat Pelindung Diri (Lead Apron dan Thyroid Shield) di Instalasi Radiologi Rumah Sakit PKU Muhammadiyah Yogyakarta, dilakukan melalui observasi dan pengujian. Berdasarkan hasil observasi alat pelindung diri yang telah dilakukan oleh peneliti, tersedia empat buah Lead Apron dan satu buah Thyroid Shield dengan kondisi fisik yang berbeda-beda pada masing-masing Lead Apron ataupun Thyroid Shield. Radiologi RS PKU Muhammadiyah Yogyakarta diletakkan pada tiap ruangan yang berbeda-beda. Lead Apron di ruang pemeriksaan satu disimpan dengan digantung pada hanger dan diletakan diatas tabir perisai. Lead Apron di ruang pemeriksaan dua disimpan dengan cara ditekuk diatas tabir perisai. Lead Apron terletak di ruang pemeriksaan $C T$ Scan dengan posisi disimpan secara tidak beraturan dan kadang dilipat-lipat. Sedangkan untuk Lead Apron yang berada di ruang pemeriksaan $I C U$ diletakan dipunggung tabir perisai radiasi. Thyroid Shield terletak pada ruang pemeriksaan satu yang disimpan dilemari obat dengan posisi dilipat-lipat secara tidak beraturan. Untuk perawatan keempat Lead Apron dan Thyroid Shield tersebut tidak ada perawatan khusus yang dilakukan secara rutin. Perawatan yang akan dilakukan hanya pada saat Lead Apron terlihat sangat kotor. Maka Lead Apron dan Thyroid Shield akan dibersihkan menggunakan Meliseptol Pure dengan cara mengelap pada pembungkus Lead Apron dan Thyroid Shield.

Dari hasil pengujian terhadap empat buah Lead Apron dan Thyroid Shield diperoleh hasil pada Lead Apron A dapat dijelaskan bahwa kuadran I,II, dan III memiliki kondisi timbal yang cukup baik karena tidak terdapat robekan ataupun patahan pada permukaan timbal. Sedangkan untuk Lead Apron A kuadran IV terdapat patahan bekas lubang jahitan yang menjadi garis disebelah sisi kanan atas. Akan tetapi pada Lead Apron A kuadran I, II, III dan IV juga terdapat lekukan-lekukan yang ditandai dengan adanya gambar seperti gelombang berwarna putih dibeberapa tempat. Lead Apron B kuadran I, II, III, dan IV memiliki kondisi timbal yang cukup baik, karena tidak terdapat patahan ataupun retakan pada permukaan. Akan tetapi pada Lead Apron B kuadran I, II, III dan IV terdapat lekukanlekukan yang ditandai dengan adanya gambar seperti gelombang berwarna putih dibeberapa tempat sehingga permukaan Lead Apron B tidak rata. Lead Apron C kuadran I,II, III, dan IV memiliki kondisi timbal yang kurang baik karena terdapat robekan, retakan, patahan ataupun lubang pada permukaan timbal. Dan ditambah pada Lead Apron C kuadran I, II, III dan IV juga terdapat lekukan-lekukan yang ditandai dengan adanya gambar seperti gelombang berwarna putih dibeberapa tempat. Lead Apron D pada kuadran I, II, III, dan IV terlihat memiliki kondisi timbal yang cukup baik, karena pada Lead Apron D tidak terdapat 
robekan, patahan, lubang ataupun retakan pada permukaan Lead Apron D. Akan tetapi pada Lead Apron D kuadran I, II, III dan IV terdapat lekukan-lekukan atau lipatan-lipatan yang ditandai dengan adanya gambar seperti gelombang berwarna putih dibeberapa tempat pada hasil pengujian Lead Apron D. Lekukan lekukan tersebut tidak terlalu banyak terlihat di masing- masing kuadran baik kuadran I, II, III ataupun IV. Sedangkan untuk Thyroid Shield memiliki kondisi timbal yang baik, karena tidak terdapat patahan ataupun retakan pada permukaan timbal.

Gambar Lead Apron yang terdapat patahan, retakan ataupun lubang

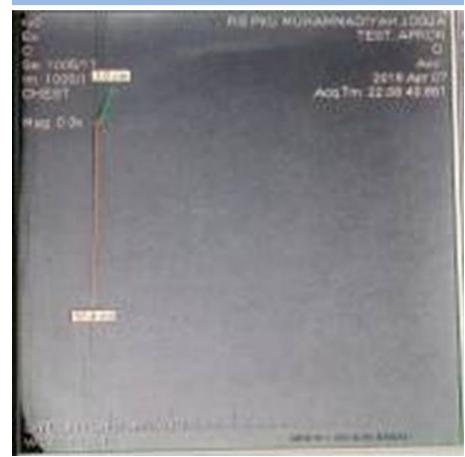

Gb. 1 Hasil pengukuran Lead Apron A Kuadran IV

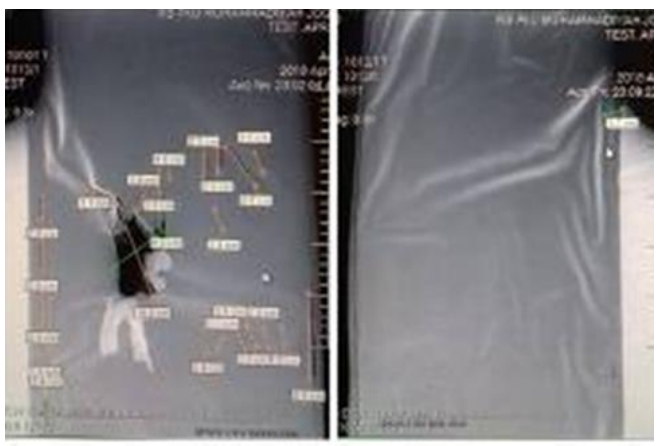

a

b

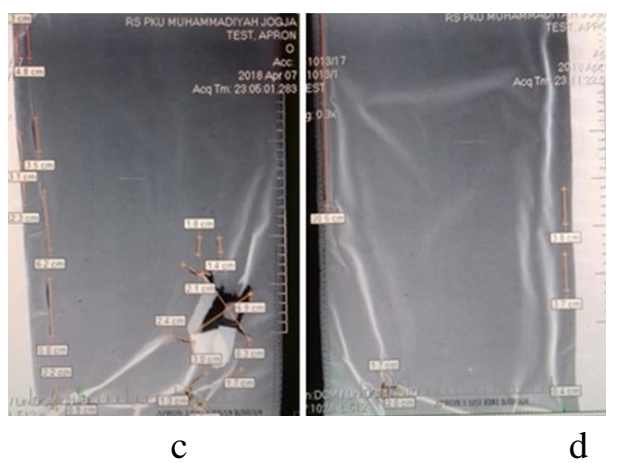

Gb. 2 Hasil pengukuran Lead Apron C
Dari hasil pengujian Lead Apron dan Thyroid Shield di Instalasi Radiologi RS PKU Muhammadiyah Yogyakarta diperoleh bahwa Lead Apron dengan kode A, B, D dan Thyroid Shield masih dalam kondisi aman bila digunakan sebagai alat pelindung radiasi sinar X. Namun, untuk Lead Apron $\mathrm{C}$ terdapat patahan, lubang ataupun robekan yang kecil-kecil disetiap kuadran Lead Apron maka Lead Apron $\mathrm{C}$ sudah tidak layak atau aman jika digunakan.

2. Pembahasan

Di Instalasi Radiologi RS PKU Muhammadiyah Yogyakarta perawatan Lead Apron dan Thyroid Shield tidak menjadi kegiatan rutin ataupun wajib karena dalam pelaksanaannya Lead Apron dan Thyroid Shield hanya dibersihkan ketika terlihat kotor ataupun jarang sekali dibersihkan. Pembersih yang digunakan untuk Lead Apron dan Thyroid Shield yaitu dengan menggunakan Meliseptol Pure dengan cara dilap dengan menggunakan kain biasa. Sedangkan untuk peletakan Lead Apron yaitu dengan cara diletakan digantung dengan menggunakan hanger baju, di sandarkan di balik tabir $P b$ dengan posisi terlipat bagian tengah, diletakan secara tidak beraturan. Peletakan Lead Apron tersebut dapat menyebabkan regangan antar bagian pada Lead Apron yang akan menimbulkan patahan ataupun retakan.

Menurut penulis perawatan Lead Apron dan Thyroid Shield dapat berupa penyimpanan dan pembersihan. Untuk penyimpanan Lead Apron dan Thyroid Shield di Instalasi Radiologi PKU Muhammadiyah Yogyakarta masih diletakkan secara tidak beraturan, yaitu seperti digantung, dilipat diatas tabir lalu dilipat diletakkan dilemari obat maka dari itu didukung dengan teori Grover (2002) peneliti menyarankan sebaiknya Lead Apron dan Thyroid Shield disimpan dalam lemari khusus dengan posisi horizontal agar timbal penyusun Lead Apron dan Thyroid Shield tetap dalam kondisi baik dan tidak mengalami penurunan fungsi.

Sedangkan untuk pembersihan Lead Apron dan Thyroid Shield di Instalasi Radiologi PKU Muhammadiyah Yogyakarta dilakukan menggunakan Meliseptol Pure ketika Lead Apron dan Thyroid Shield terkena media kontras maupun percikan darah pasien. Menurut peneliti dengan didukung dengan teori Llyod (2001), sebaiknya Lead Apron dan Thyroid 
Shield dibersihkan secara rutin dengan menggunakan shampo dan air, tidak membersihkan menggunakan alkohol karena dapat menyebabkan kain pembungkus terkikis dan sobek. Dan bila perlu dilakukan pembuatan Standar Operasional Pemeliharaan dan pengujian Lead Apron dan Thyroid Shield agar Lead Apron dan Thyroid Shield dapat terjaga dengan baik.

Lead Apron A yang dibeli pada tahun 1997 dengan ketebalan bagian depan $0,35 \mathrm{~mm}$ serta ketebalan bagian belakang $0,25 \mathrm{~mm}$. Setelah dilakukan pengujian diruang pemeriksaan satu, diperoleh hasil terdapat lekukan di keempat kuadran. Tetapi lekukan terparah terdapat di kuadran tiga, lekukan tersebut ditandai dengan warna putih. Dan terdapat garis hitam disekitar kuadran empat, yaitu terdapat patahan bekas lubang jahitan yang menjadi garis sepanjang $17,4 \mathrm{~cm}(174 \mathrm{~mm})$ dan $3,0 \mathrm{~cm}(30 \mathrm{~mm})$. Hal ini disebabkan karena penempatan Lead Apron yang digantung dan terkadang dilipat diatas tabir $P b$. Meskipun terdapat kecacatan, Lead Apron A ini masih dalam kondisi aman, karena kecacatan tidak berada didaerah vital, dan masuk dalam kategori kerusakan tidak signifikan. Sehingga Lead Apron masih aman untuk digunakan.

Lead Apron B dibeli pada tahun 2007 dengan tebal Lead Apron 0,35 serta ketebalan bagian belakang 0,25 mm. Lead Apron B setelah dilakukan pengujian diruang pemeriksaan satu diperoleh hasil bahwa terdapat lekukan-lekukan yang ditandai dengan warna putih pada setiap bagian kuadran Lead Apron B. Hal ini disebabkan karena Lead Apron $\mathrm{B}$ diletakan dengan cara terlipat di tabir $\mathrm{Pb}$ dan perawatan yang diberikan kurang baik.

Lead Apron C dibeli pada tahun 2007 dengan tebal Lead Apron 0,35 mm serta ketebalan bagian belakang $0,25 \mathrm{~mm}$. Setelah dilakukan pengujian diruang pemeriksaan satu dapat dilihat hasil bahwa terdapat lekukan yang lumayan parah disertai dengan lubang dan retakan. Lead Apron C pada kuadran I terdapat lubang dengan panjang $10,8 \mathrm{~cm}(108 \mathrm{~mm})$ dan lebar $5,5 \mathrm{~cm}(55 \mathrm{~mm})$ yang diperoleh luasan $59,4 \mathrm{~cm}^{2}\left(5940 \mathrm{~mm}^{2}\right)$, lalu terdapat patahan akibat lubang bekas jahitan yaitu sepanjang 2,4 $\mathrm{cm}(24 \mathrm{~mm}), 3,0 \mathrm{~cm}(30 \mathrm{~mm}), 2,9 \mathrm{~cm}(29 \mathrm{~mm})$, $1,4 \mathrm{~cm}(14 \mathrm{~mm})$ dan $2,4 \mathrm{~cm}(24 \mathrm{~mm})$. Lalu robekan kecil-kecil sebesar 2,0 cm ( $20 \mathrm{~mm})$, $2,5 \mathrm{~cm}(25 \mathrm{~mm}) \quad 4,9 \mathrm{~cm}(49 \mathrm{~mm}), 2,1 \mathrm{~cm}(21$ $\mathrm{mm}), 2,3 \mathrm{~cm}(23 \mathrm{~mm}), 2,4 \mathrm{~cm}(24 \mathrm{~mm}), 1,1, \mathrm{~cm}$ $(11 \mathrm{~mm}), 2,6 \mathrm{~cm}(26 \mathrm{~mm}), 2,0 \mathrm{~cm}(20 \mathrm{~mm}), 2,2$ $\mathrm{cm}(22 \mathrm{~mm}), 1,8 \mathrm{~cm}(18 \mathrm{~mm})$ pada permukaan kuadran I Lead Apron C. Sedangkan untuk kuadran II terdapat robekan 2,2 cm (22 mm). Lalu untuk kuadran III terdapat lubang dengan panjang $8,3 \mathrm{~cm}(83 \mathrm{~mm})$ dan lebar $5,7 \mathrm{~cm}(53$ $\mathrm{mm}$ ) yang diperoleh luasan $49,02 \mathrm{~cm}^{2}$ (4902 $\mathrm{mm}^{2}$ ), lalu terdapat patahan akibat lubang bekas jahitan dibeberapa tempat yaitu sepanjang 4,8 $\mathrm{cm}(48 \mathrm{~mm}), 3,5 \mathrm{~cm}(35 \mathrm{~mm}), 6,2 \mathrm{~cm}(62 \mathrm{~mm})$, $5,8 \mathrm{~cm}(58 \mathrm{~mm})$ dan $2,2 \mathrm{~cm}(22 \mathrm{~mm})$, lalu juga terdapat retakan-retakan kecil $1,8 \mathrm{~cm}(18 \mathrm{~mm})$, $1,4 \mathrm{~cm}(14 \mathrm{~mm}), 2,1 \mathrm{~cm}(21 \mathrm{~mm}), 2,4 \mathrm{~cm}(24$ $\mathrm{mm}), 3,0 \mathrm{~cm}(30 \mathrm{~mm}), 1,0 \mathrm{~cm}(10 \mathrm{~mm}), 1,7 \mathrm{~cm}$ (17 $\mathrm{mm})$ dan $1,3 \mathrm{~cm}(13 \mathrm{~mm})$. Sedangkan untuk kuadran IV terdapat lubang dengan panjang 2,0 $\mathrm{cm}(20 \mathrm{~mm})$ dan lebar $1,7 \mathrm{~cm}(17 \mathrm{~mm})$ yang diperoleh luasan $3,4 \mathrm{~cm}^{2}\left(340 \mathrm{~mm}^{2}\right)$ lalu terdapat patahan akibat lubang bekas jahitan dibeberapa tempat yaitu sepanjang $3,7 \mathrm{~cm}$ (37 $\mathrm{mm})$ dan $3,8 \mathrm{~cm} \quad(38 \mathrm{~mm})$. Hasil ini menandakan bahwa Lead Apron C sudah tidak layak untuk digunakan.

Lead Apron D dibeli pada tahun 2016 dengan ketebalan Lead Apron 0,35 mm. Setelah dilakukan pengujian diruang pemeriksaan satu dapat dilihat hasil bahwa terdapat lekukan yang tidak cukup parah pada bagian Lead Apron D. Maka dari itu Lead Apron D masih aman untuk digunakan.

Thyroid Shield dilakukan pengujian diruang pemeriksaan satu dapat dilihat bahwa terdapat lekukan yang tidak cukup parah pada Thyroid Shield sehingga masih aman untuk digunakan.

Menurut pendapat peneliti setelah memadukan teori Oyar dan Arzu (2012) dengan teori Roser (2010), pada hasil pengujian empat buah Lead Apron dan satu buah Thyroid Shield di instalasi Radiologi RS PKU Muhammadiyah Yogyakarta jika didasarkan sesuai dengan teori yang ada diperoleh hasil bahwa Lead Apron A dikategorikan pada jenis kerusakan insignificant (tidak signifikan) yaitu kerusakan yang tidak membahayakan, tetapi tetap diperlukan pengawasan dan pengujian secara berkala. Tetapi jika menurut Oyar dan Arzu (2012) maka patahan tersebut sudah melebihi batas maksimal, namun kerusakan yang terjadi berada diarea non vital sehingga masih aman untuk digunakan. Sedangkan untuk Lead Apron C sudah tidak layak untuk digunakan karena terdapat lipatan yang parah ditandai dengan 
warna putih dan terdapat banyak retakan ataupun lubang pada permukaan Lead Apron C yang terletak menyebar yang sudah melebihi standar yang ditentukan sebaiknya Lead Apron $\mathrm{C}$ sudah tidak digunakan lagi untuk pelindung dari bahaya radiasi sinar $\mathrm{X}$ dan perlu untuk diganti. Sedangkan untuk Lead Apron B, D dan Thyroid Shield masih dalam keadaan yang bagus dan layak untuk digunakan walaupun Lead Apron banyak mengalami lekukan.

3. Kesimpulan

Berdasarkan hasil dan pembahasan tersebut dapat disimpulkan :

a. Perawatan Lead Apron dan Thyroid Shield di Instalasi Radiologi RS PKU Muhammadiyah Yogyakarta dibagi kedalam penyimpanan dan pembersihan. Penyimpanan Lead Apron diletakkan digantung secara vertikal menggunakan hanger di tabir $P b$, dilipat di tabir $P b$, diletakkan secara tidak beraturan dengan posisi terlipat-lipat dan untuk Thyroid Shield diletakkan secara terlipat di lemari obat. Sedangkan untuk pembersihan Lead Apron dan Thyroid Shield dilakukan dengan cara membersihkan pembukus $P b$ dengan alkohol Meliseptol Pure saat terkena media kontras ataupun percikan darah dari pasien.

b. Pengujian terhadap empat buah Lead Apron dan satu buah Thyroid Shield didapatkan hasil yaitu Lead Apron C mengalami kebocoran karena adanya kerusakan yaitu pada kuadran I, III dan IV berupa lubang yang melebihi diameter 2 $\mathrm{mm}$ atau luas $3,14 \mathrm{~mm}^{2}$ dan retakan atau patahan yang lebih dari $4 \mathrm{~mm}$. Maka dari itu Lead Apron C sudah tidak aman untuk digunakan. Sedangkan untuk Lead Apron A, B, D dan Thyroid Shield masih dalam kondisi aman digunakan sebagai alat pelindung radiasi.

c. Berdasarkan hasil pengujian terhadap ke empat buah Lead Apron dan satu buah Thyroid Shield di Instalasi Radiologi RS PKU Muhammadiyah Yogyakarta, Lead Apron C sudah tidak layak sedangkan untuk Lead Apron A, B, D dan Thyroid Shield masih dalam kondisi layak.

\section{Saran}

a. Sebaiknya Lead Apron dan Thyroid Shield di Instalasi radiologi RS PKU Muhammadiyah Yogyakarta diperhatikan perawatannya, perawatan disini meliputi penyimpanan atau penempatan dan pembersihan pada Lead Apron dan Thyroid Shield.

b. Mengingat kondisi timbal pada Lead Apron dan Thyroid Shield tidak dapat dilihat dengan kondisi kasat mata maka perlu dilakukan pengujian terhadap Lead Apron dan Thyroid shield selama satu tahun sekali yang digunakan untuk memantau kondisi timbal dari Lead Apron dan Thyroid shield.

c. Lead Apron yang rusak sebaiknya disimpan dan tidak digunakan sebagai alat pelindung radiasi.

\section{Daftar Pustaka}

Akhadi, Mukhlis. 2000. Dasar-dasar Proteksi Radiasi. Jakarta: Rineka Cipta

Brennan, P.C., Finnerty, M. 2005. Protective aprons in imaging departements: manufacture stated lead equivalence value require validation. $\mathrm{St}$ Anthony's, Herbert Avenue, Dublin 4, Ireland.

Grover, SB., Kumar, J., Gupta, A., Khanna, L, 2002. Protection againt radiation hazard : Regulatory bodies, safety norms, does limits abd protection devices, Department of Radiology, vardhaman Mahavir Medical College \& Safdarjang Hospital,India.

Han, Cheng, and Ma, 2013. Shielding effect of Thyroid collar for digital panoramic radiography. www.ncbi.nlm.nih.gov diakses tanggal 15 januari 2018 pukul 09.00

Jamie, Tomas, 2008. Protection Radiation In Medicine, Tylor \& Francis Group, Series in Medical Physics and Biomedical Engineering

Lambert, K and McKeon, T, 2001, "Inspection of Lead Apron : Kriteria For Rejection" Operational Radiation Safety, Suplement To Health Physics, 80, Suppl 5, May 2001, S67-S69

Lloyd, Peter J, 2001. Quality Assurance workbook for radiographer \& radiological technologist. Diagnostik Imaging and Laboratory Technology. WHO. Geneva.

Oyar, Orhan, Arzu. 2012. How protective are the lead apron we use against ionizing radiation?. Izmir Katip Celebi University. Turkey.

Perka Bapeten no 8 tahun 2011 tentang Keselamatan Radiasi Dalam Penggunaan Pesawat Sinar-X Radiologidiagnostik dan Intervensional

Rasad, Sjahrir. 2005. Radiologi Diagnostik. Jakarta: FK UI.

Rudi, Pratiwi dan Susilo, 2012, Pengukuran Paparan Radiasi Pesawat Sinar-X di Instalasi Radiodiagnostik untuk Proteksi Radiasi, Unnes Physics Journal, Vol.1, No1, Jur.FisikaUnnes, hal 20.

Roser. 2010. Quality Assurance of X Ray Protection Clothing at the University Hospital Basel. 
http://www.ssrpm.ch diakses tanggal 13 Januari 2018 pukul 13.00

Statkiewicz, Paula, Russell and Kelli, 2014 “ Radiation Protection In Medical Radiography" Elsevier Mosby, ISBN: 978-0-323-17220-2.

Suyatno, Ferry, 2008. "Aplikasi Radiasi Sinar-X Di Bidang Kedokteran Untuk Menunjang Kesehatan Masyarakat”, Sekolah Tinggi Teknologi Nuklir, ISSN 1978-0176.

Syamsul Bahri, 2005."Variasi tegangan pemercepat terhadap spekrum sinar-X untuk absorber Cu dan Al', Jurnal Gradien Vol.1 No.1 Januari 2005 : 6-9.

Yulihendra, 2002. Alat Proteksi Diri. Digilib.unimus.ac.id diakses tanggal 10 Januari 2018 pukul 20.00 